INTESTINE

\title{
Arginine stimulates intestinal cell migration through a focal adhesion kinase dependent mechanism
}

\author{
J M Rhoads, W Chen, J Gookin, G Y Wu, Q Fu, A T Blikslager, R A Rippe, R A Argenzio, \\ W G Cance, E M Weaver, L H Romer
}

See end of article for authors' affiliations

....................

Correspondence to: Dr J M Rhoads, Pediatric Gastroenterology,

Ochsner for Children,

1514 Jefferson Hwy, New Orleans, LA 70121, USA;

mrhoads@ochsner.org

Accepted for publication 30 October 2003
Background: L-Arginine is a nutritional supplement that may be useful for promoting intestinal repair. Arginine is metabolised by the oxidative deiminase pathway to form nitric oxide (NO) and by the arginase pathway to yield ornithine and polyamines.

Aims: To determine if arginine stimulates restitution via activation of $\mathrm{NO}$ synthesis and/or polyamine synthesis.

Methods: We determined the effects of arginine on cultured intestinal cell migration, NO production, polyamine levels, and activation of focal adhesion kinase, a key mediator of cell migration.

Results: Arginine increased the rate of cell migration in a dose dependent biphasic manner, and was additive with bovine serum concentrate (BSC). Arginine and an NO donor activated focal adhesion kinase (a tyrosine kinase which localises to cell matrix contacts and mediates $\beta 1$ integrin signalling) after wounding. Arginine stimulated cell migration was dependent on focal adhesion kinase (FAK) signalling, as demonstrated using adenovirus mediated transfection with a kinase negative mutant of FAK. Arginine stimulated migration was dependent on NO production and was blocked by NO synthase inhibitors. Arginine dependent migration required synthesis of polyamines but elevating extracellular arginine concentration above $0.4 \mathrm{mM}$ did not enhance cellular polyamine levels.

Conclusions: These results showed that L-arginine stimulates cell migration through NO and FAK dependent pathways and that combination therapy with arginine and BSC may enhance intestinal restitution via separate and convergent pathways.
A fter acute mucosal injury, rapid restoration of epithelial continuity depends on migration of uninjured epithelial cells to cover denuded sections of basement membrane. ${ }^{1}$ Enterocyte migration is a mitosis independent process that is completed within 6-12 hours. Cell adhesion and migration are mediated by key cytoskeletal and signalling proteins that are organised in lamellipodial extensions. ${ }^{2}$ At these focal adhesions, numerous proteins colocalise, including p120 focal adhesion kinase (FAK), ${ }^{3}$ talin, alpha-actinin, vinculin, paxillin, p130Cas, and p60c-src. Several of these proteins are phosphorylated and activated by FAK. ${ }^{4-8}$

Arginine (ARG) has been reported to lessen intestinal damage in animal models of necrotising enterocolitis. ${ }^{9-11}$ ARG is metabolised by two major pathways in enterocytes: conversion by arginase to ornithine, the precursor of polyamines, and conversion by nitric oxide synthase (NOS) to nitric oxide (NO) and citrulline. Polyamines are polycations that are required for normal formation of lamellipodia and stress fibres during cell migration. NO is a lipophilic free radical that stimulates mucus secretion and water absorption, produces smooth muscle relaxation, and regulates bowel permeability. ${ }^{12}{ }^{13}$ In the current studies, we determined the effect of ARG on enterocyte migration through FAK phosphorylation after wounding of cultured cells ${ }^{14}$ as a first step in intestinal repair. Bovine serum concentrate (BSC) was used as a positive control. BSC has been shown by our group to facilitate intestinal villous regrowth and improve bowel permeability in experimental cryptosporidial diarrhoea, ${ }^{15}$ and serum activates ornithine decarboxylase (ODC) in intestinal cells. ${ }^{16}$ BSC is inexpensive and approved by the United States Department of Agriculture for use as a dietary supplement (Immunolin or NutraGammax; Proliant Inc., Ames, Iowa, USA) in health food stores. BSC contains active IgG, IgM, and IgA, transforming growth factor $\beta$ (TGF- $\beta$ ), and insulinlike growth factor 1 (IGF-1).

\section{METHODS}

Chemicals

Acrylamide and bisacrylamide were from National Diagnostics (Atlanta, Georgia, USA). Protease and phosphatase inhibitors (aprotinin, leupeptin, bestatin, 4-nitrophenyl phosphate, pepstatin, dithiothreitol, and NP-40) were from Boehringer Mannheim (Indianapolis, Indiana, USA). Herbimycin was from Gibco BRL (Gaithersburg, Maryland, USA). Tyrphostins (AG213 and 216) were from Professor Alex Levitski (Hebrew University, Jerusalem, Israel). BSC was obtained from Proliant Inc. (Ames, Iowa, USA). BSC powder contains approximately $80 \%$ protein, of which $60 \%$ is albumin and $25 \%$ is immunoglobulin G (IgG). The manufacturer has measured significant levels of IGF-I (6000 ng/g protein) and TGF- $\beta 1$ (90 ng/g) in BSC. All other chemicals, including 3,3-bis(aminoethyl)-1-hydroxy-2-oxo-1-triazene (Deta-NONOate), were obtained from Sigma (St Louis, Missouri, USA).

Abbreviations: ARG, L-arginine; BSC, bovine serum concentrate; DFMO, difluoromethyl-ornithine; Deta-NONOate, 3,3-bis(aminoethyl)1-hydroxy-2-oxo-1-triazene; DMEM, Dulbecco's modified Eagle's medium; FAK, focal adhesion kinase; FBS, fetal bovine serum; iNOS, inducible nitric oxide synthase; IGF-1, insulin-like growth factor 1; L-Nil, $\mathrm{L}-\mathrm{N} 6\left(1\right.$-iminoethyl)lysine; NEC, necrotising enterocolitis; NMMA, $L-N^{G}$ monomethyl arginine; NO, nitric oxide; NOS, nitric oxide synthase; ODC, ornithine decarboxylase; PBS, phosphate buffered saline; PUT, putrescine; SDS-PAGE, sodium dodecyl sulphate-polyacrylamide gel' electrophoresis; TGF- $\beta$, transforming growth factor $\beta$ 


\section{Antibodies}

Mouse monoclonal antibody IgGl to FAK (clone 4.47) was obtained from Upstate Biotechnology (Lake Placid, New Jersey, USA). Mouse monoclonal antiphosphotyrosine (PY20) and rabbit polyclonal anti-nitric oxide sythase II (antiNOS II) antibodies were obtained from Transduction Laboratories (Lexington, Kentucky, USA).

\section{Cells}

We selected IPEC-J2 cells derived from newborn piglet jejunum because of their differentiated characteristics, ${ }^{17}$ and Cdx2 transformed IEC-6 cells because of a more differentiated phenotype, including a fourfold increased rate of cell migration. $^{18}{ }^{19}$ IPEC-J2 cells were obtained from $\mathrm{H}$ Berschneider (North Carolina State University College of Veterinary Medicine, Raleigh, North Carolina, USA). IPEC-J2 cells were grown in Dulbecco's modified Eagle's medium (DMEM)/F12 medium with 5\% serum, split weekly, and were studied at passages 28-56. The Cdx2 transformed rat crypt cell line IEC-6 ${ }^{18} 19$ was obtained from Dr J-Y Wang (University of Maryland, Baltimore, USA). Cdx2 transformed IEC-6 cells were cultured in DMEM with isopropyl- $\beta$-Dthioguanine ( $4 \mathrm{mM})$, which served as the inducer for $C d x 2$ directed by the LacSwitch system (Stratagene, La Jolla, California, USA), for four weeks prior to the experiments and were studied at passages 5-20.

\section{Migration assay}

Cells were plated in six well Costar (Corning, New York, USA) plates. After reaching confluence, cells were serum starved overnight in DMEM to achieve quiescence. DMEM contains $0.4 \mathrm{mM}$ ARG. In studies of Cdx2 transformed IEC-6 cells, cells were transferred to amino acid free media for six hours (BME with Earle's salts; Atlanta Biologicals, Norcross, Georgia, USA). Mitomycin C $(2 \mu \mathrm{g} / \mathrm{ml})$ was added. Preliminary studies showed that mitomycin $C$ fully inhibited IPEC-J2 cell proliferation at 24 hours. Treatments were added 15 minutes before razor injuring, and inhibitors (L$N^{\mathrm{G}}$-monomethyl arginine (NMMA) ${ }^{20}$ or difluoromethylornithine (DFMO), an irreversible inhibitor of ODC) were added three or 12 hours before treatments, respectively. The distance at which cells at the leading edge had migrated ${ }^{2}$ was measured and expressed as surface area covered by cells (in $\mu \mathrm{m}^{2}$ ) per $\mu \mathrm{m}$ of linear wound.

\section{Measurement of nitrite production}

To maximise the number of cells migrating, monolayers were wounded 20 times with a pipette tip. Media samples were collected 24 hours later. Production of nitrite, a stable metabolite of NO, was measured by a Griess reaction assay kit (G-4410) according to the manufacturer's instructions (Sigma).

\section{Intracellular polyamine assay}

Twenty four hours after wounding, cells were washed with phosphate buffered saline (PBS) twice and collected in polystyrene tubes. Half of the cell pellet was used to measure total cell protein and half of the pellet was used for polyamine measurement, as previously described..$^{21}$ For each $5 \times 10^{6}$ cells, we added $0.2 \mathrm{ml}$ of $1.5 \mathrm{M} \mathrm{HClO}_{4}$. After five minutes, $0.1 \mathrm{ml}$ of $2 \mathrm{M} \mathrm{K}_{2} \mathrm{CO}_{3}$ was added and mixed for another two minutes. After centrifugation at $3000 \mathrm{~g}$, the supernatant was stored at $-80^{\circ} \mathrm{C}$ for polyamine measurement. Polyamines were quantified on the basis of standards.

\section{Immunocytochemical staining for iNOS}

Cdx2 transformed IEC- 6 cells were wounded for 12 hours and fixed for five minutes at $10^{\circ} \mathrm{C}$ in methanol. Cells were treated with $10 \%$ goat serum and then incubated with rabbit
anti-iNOS antibodies (Transduction Laboratories) (1:200) for one hour at $4^{\circ} \mathrm{C}$. After several rinses with PBS, cells were further incubated for 45 minutes with fluorescein conjugated secondary antibody (goat antirabbit) in PBS.

\section{Phosphotyrosine analysis}

FAK immunoprecipitation and immunoblotting for FAK and phosphotyrosine were done according to previously published protocols. ${ }^{23}$ Briefly, cells were "starved" of serum and amino acids in Earle's balanced salts solution for four hours. After wounding, cell migration, and washing, $10^{7}$ cells were scraped in lysis buffer ( $150 \mathrm{mM} \mathrm{NaCl}, 0.1 \% \mathrm{NaN}_{3}, 50 \mathrm{mM}$ Tris $\mathrm{HCl}$ ( $\mathrm{pH} 7.6), 2 \mathrm{mM}$ Na orthovanadate, $2 \mu \mathrm{g} / \mathrm{ml}$ aprotinin, $2 \mu \mathrm{g} / \mathrm{ml}$ leupeptin, $2 \mathrm{mg} / \mathrm{ml}$ phenyl methyl sulphonyl fluoride, $0.1 \%$ triton $\mathrm{X}-100$, and $0.1 \% \mathrm{Na}^{+}$deoxycholate) at $4^{\circ} \mathrm{C}$. Cell lysates were then clarified by centrifugation for 10 minutes at $15000 \mathrm{~g}$ and lysate volumes were normalised for protein content. The supernatants were incubated with anti-FAK antibody (Upstate Biotechnology) at $4^{\circ} \mathrm{C}$ for a minimum of 90 minutes. Rabbit antimouse IgG (Jackson ImmunoResearch, West Grove, Pennsylvania, USA) bound to protein A sepharose was then added and incubated with mixing for a minimum of 90 minutes at $4^{\circ} \mathrm{C}$. Beads were sedimented and washed extensively with lysis buffer. Proteins were then released for sodium dodecyl sulphatepolyacrylamide gel electrophoresis (SDS-PAGE) and blot analysis by boiling in Laemmli sample buffer with $1 \mathrm{mM}$ $\mathrm{Na}$ orthovanadate for three minutes. Samples were electrophoresed on $8 \%$ SDS-PAGE and transferred to nitrocellulose. After blocking with $1 \%$ bovine serum albumin in Tris buffered saline with $0.05 \%$ Tween-20 for one hour, membranes were incubated with horseradish peroxidase conjugated PY20 (ICN Biochemicals Inc., Costa Mesa, California, USA) for one hour and developed using enhanced chemiluminescence (Amersham Corp., Arlington Heights, Illinois, USA). After stripping of the antiphosphotyrosine antibody with $100 \mathrm{mM} \beta$-mercaptoethanol and $0.2 \%$ SDS in $62.5 \mathrm{mM}$ Tris- $\mathrm{HCl}, \mathrm{pH} \mathrm{6.7,} \mathrm{the} \mathrm{membrane} \mathrm{was} \mathrm{washed} \mathrm{and} \mathrm{then}$ blocked with $5 \%$ dry milk in Tris buffered saline with 0.05\% Tween-20 for one hour. Anti-FAK immunoblotting was then accomplished using the anti-FAK antibody, horseradish peroxidase conjugated antimouse IgG secondary antibody, and enhanced chemiluminescence.

\section{Adenoviral transfection of IEC- 6 cells}

Ad5FAK-CD contains a dominant negative version of FAK lacking the $\mathrm{N}$ terminus and the kinase domain. ${ }^{24}$ Ad5Luc contains the luciferase reporter gene $5^{\prime}$ of the adenovirus promoter and was used as a control virus. IEC- 6 cells, after a 24 hour period of culture in DMEM with $0.5 \%$ serum, were infected with Ad5FAK-CD or Ad5Luc at a multiplicity of infection of 500 for 12 hours in DMEM with $10 \%$ fetal bovine serum (FBS). The infection medium was changed to fresh $0.2 \%$ FBS medium, and cells were incubated for an additional 24 hours. The efficiency of viral transfection was assessed using an antibody directed to the carboxy terminus of FAK (antibody 5158, produced by L Romer). Western blots of Ad5FAK-CD transfected cells revealed a dense band at a molecular weight of $42-44 \mathrm{kDa}$, indicating expression of FAK-CD. There was no FAK immunoreactive band at a molecular weight of $45 \mathrm{kDa}$ in control cells.

\section{Statistics}

Results in the text and figures are expressed as mean (SEM). Statistical significance of differences $(p \leqslant 0.05)$ between mean values was assessed with one way ANOVA and a post hoc Tukey's test. For analysis of additivity of ARG and BSC, we used a regression model with surface area of cell migration as the response and variables ARG, BSC, and 


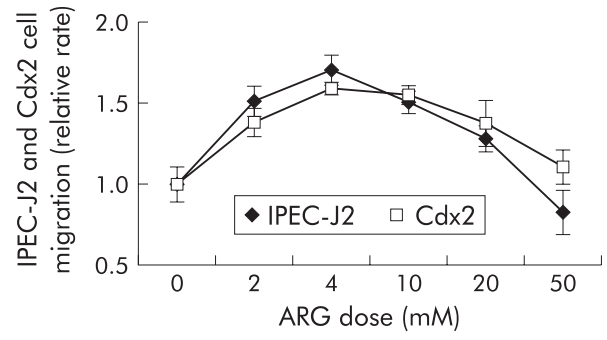

Figure 1 (A) Enhancement of IPEC-J2 cell and Cdx2-IEC-6 cell migration by arginine (ARG): dose response. Cells were serum starved overnight and then changed to Dulbecco's modified Eagle's medium (DMEM) with different concentrations of ARG (with no serum) one hour prior to wounding. Cells were incubated in DMEM, and additional ARG was added after wounding (DMEM without supplemental ARG contains $0.4 \mathrm{mM}$ ARG.) After migration, cells were fixed in $2 \%$ formaldehyde in phosphate buffered saline. Surface area covered by migrating cells was measured 18 hours later for IPEC-J2 cells and six hours later for Cdx2 transformed IEC-6 cells. Computer assisted morphometry allowed quantitation of the area covered in front of a $1 \mu \mathrm{m}$ wound at $40 \times$ magnification. Shown are means (SEM) of four experiments, with triplicate measurements for each experiment. Data were normalised for control cells with $0 \mathrm{mM}$ ARG added to media. (Surface area of migration for IPEC-J2 cells with $0 \mathrm{mM}$ added ARG was 132 (7) $\mu \mathrm{m}^{2} / \mu \mathrm{m} / 24$ hours and for Cdx2 transformed IEC- 6 cells was $48(5) \mu \mathrm{m}^{2} / \mu \mathrm{m} / 6$ hours. Assuming linear rates of migration after wounding, our data indicate that Cdx2 transformed IEC- 6 cells migrate 1.5-fold faster than IPEC-J2 cells.) $p \leqslant 0.05$ compared with control cells.
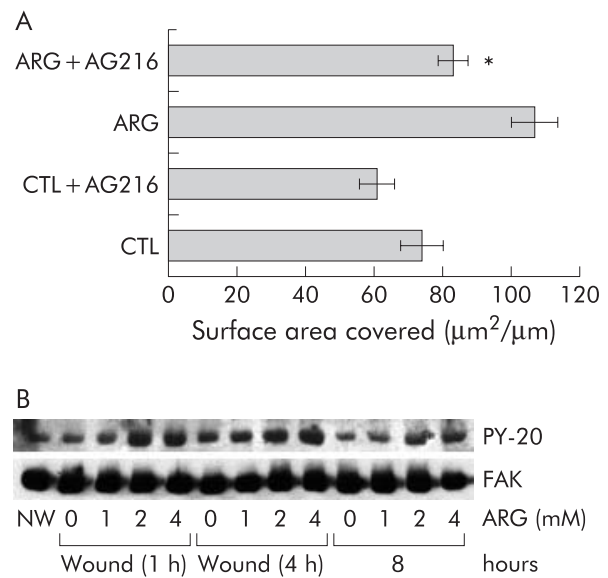

ARG+BSC interaction. The software program used was SigmaStat (Jandel Scientific, San Rafael, California, USA).

\section{RESULTS}

\section{ARG increased cell migration}

IPEC-J2 and Cdx2 cell migration was enhanced by ARG after razor wounding in a dose dependent manner (fig 1 ). Maximal stimulation of migration by ARG was seen with $4 \mathrm{mM}$ ARG, producing a 1.67-fold increase in surface area covered. Arginine stimulated migration as effectively as any other agonist tested, including $100 \mathrm{ng} / \mathrm{ml}$ epidermal growth factor (47\% enhancement); $1 \%$ fetal calf serum $(55 \%$ enhancement), and prostacyclin $(1 \mu \mathrm{M}) \quad(25 \%$ enhancement). Significant stimulation $(p \leqslant 0.05)$ was observed at an ARG concentration as low as $2 \mathrm{mM}$. Maximal effect was at $4 \mathrm{mM}$, with diminishing results above $20 \mathrm{mM}$ ARG. Similar stimulatory effects of ARG on migration rate were observed with untransformed IEC-6 cells (data not shown).

ARG was compared with five other amino acids with respect to stimulation of cell migration. Glutamate, leucine, phenylalanine, proline, and citrulline did not significantly stimulate migration. L-Glutamine produced $46 \%$ enhancement and was the only amino acid comparable to ARG. ARG in these comparative studies with other amino acids stimulated migration 1.7 -fold $(\mathrm{p} \leqslant 0.05)(\mathrm{n}=3)$.

\section{ARG stimulated migration is associated with increased tyrosine phosphorylation of FAK}

To determine if increased tyrosine phosphorylation is required for ARG stimulated intestinal cell migration, cells
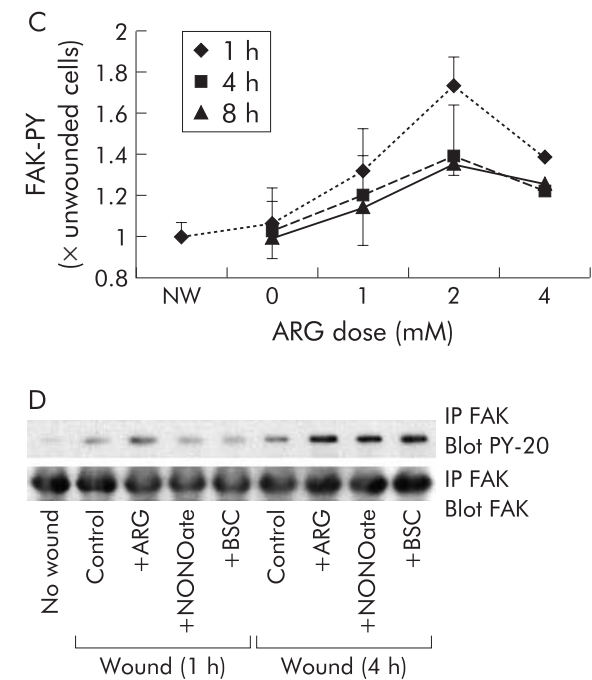

Figure 2 Relationship between tyrosine phosphorylation, phosphorylation of focal adhesion kinase (FAK), and intestinal cell migration. (A) Tyrosine kinase inhibitors inhibited cell migration. Tyrosine kinase inhibitors were added to IPEC-J2 cells 30 minutes before wounding with a razor (AG216 denotes tyrphostin). Surface area of migration was measured as described in figure 1, 24 hours after wounding; $n=3,{ }^{*} p \leqslant 0.02$ compared with L-arginine (ARG) treated cells. For control (CTL)+AG216 treated cells, surface area migrated was marginally less than in $C T L$ cells $(p=0.082)$. (B) ARG enhanced phosphorylation of FAK: effect of ARG dose and time after wounding. Cdx2 cells were starved with Dulbecco's modified Eagle's medium (DMEM) containing no serum and ARG overnight. Then, one hour before wounding, different doses of ARG were added to ARG-free DMEM. Cells were wounded and harvested at 1, 4, and 8 hours after wounding. They were immunoprecipitated with anti-FAK antibody and blotted with either antiphosphotyrosine (PY-20, top) or with anti-FAK (to control for equal loading, bottom). ARG at 2 and $4 \mathrm{mM}$ (but not $1 \mathrm{mM}$ ) stimulated phosphorylation of FAK at 1, 4, and 8 hours after wounding, with a peak effect at $1 \mathrm{~h}$ (1.7 fold increase, $\mathrm{n}=3$ observations). NW, non-wounded. (C) ARG enhanced phosphorylation of FAK: effect of ARG dose and time after wounding. Response of phosphorylated FAK-PY to ARG and time; mean (SEM) values for $n=3$ experiments. $p \leqslant 0.05$ compared with unwounded control cells. (D) ARG $(4 \mathrm{mM})$ stimulated phosphorylation of FAK at one hour after wounding while 3,3-bis(aminoethyl)-1-hydroxy-2-oxo-1-triazene (Deta-NONOate $10 \mu \mathrm{M}$ ) and bovine serum concentrate (BSC $100 \mathrm{mg} / 100 \mathrm{ml}$ ) stimulated phosphorylation of FAK by four hours. Cdx2 transformed IEC-6 cells were serum starved overnight and harvested, or switched to medium (one hour before wounding) containing DMEM without ARG (wound), ARG, or BSC. Cells were multiply wounded with a pipette tip and were harvested one or four hours later. They were immunoprecipitated (IP) with anti-FAK antibody and immunoblotted using either antiphosphotyrosine antibody (PY-20) or anti-FAK (to ensure equal loading). Densitometry analysis revealed that relative to that of control unwounded cells, FAK phosphorylation increased in wounded monolayers by twofold at one and four hours. Furthermore, ARG stimulated phosphorylation of FAK by threefold at one hour and by sixfold at four hours. Deta-NONOate and BSC treated cells had identical phosphorylation as control wounded cells at one hour and 2.5-fold increased phosphorylation of FAK at four hours. 
were wounded in the presence or absence of an inhibitor of tyrosine kinases, tyrphostin (AG216). Cells were grown on plastic because adhesion to exogenous matrix proteins increases the activation of FAK. ${ }^{25} \mathrm{Cdx} 2$ transformed IEC-6 cells treated with AG216 migrated at a rate that was $\sim 80 \%$ of normal ( $p=0.08, n=3)$. Cell monolayers were wounded and incubated with control medium or ARG \pm AG216. Response to ARG was inhibited by addition of AG2 16 to $~ 75 \%$ of that of ARG treated cells $(p \leqslant 0.05)$ (fig 2 ). IPEC-J2 cellular response to ARG was blocked by two other tyrosine kinase inhibitors (herbimycin A $10 \mu \mathrm{M}$; tyrphostin $47200 \mu \mathrm{M}$, data not shown).

The effect of ARG on tyrosine phosphorylation of FAK was determined by incubating cells with different concentrations of ARG (0-4 mM) after razor wounding. FAK was immunoprecipitated from lysates of each treatment group, and FAK tyrosine phosphorylation was evaluated by western blotting. ARG treatment after wounding increased tyrosine phosphorylation of FAK at 1-4 hours post-wounding. The maximal effect was seen with $2 \mathrm{mM}$ ARG, which increased the phosphotyrosine content of FAK $1.75(0.2)$-fold $(p=0.038$, $\mathrm{n}=3$ ) at one hour after wounding (fig 2B). Tyrphostin AG216 markedly reduced ARG induced changes in FAK phosphorylation (data not shown). Enhancement of FAK activity by ARG persisted at four and eight hours (fig 2B, 2C). The NO donor Deta-NONOate also stimulated FAK phosphorylation by 2.5 -fold at four hours post-wounding $(\mathrm{n}=3$, fig 2D).

\section{Role of NO in ARG stimulated migration}

We determined if ARG treatment enhanced nitrite levels in the media as an index of NO production. Nitrite levels were measured at 24 hours after injury. The "baseline" concentration of nitrite in the growth medium of normal unwounded IPEC-J2 cells was $6.5(0.5) \mu \mathrm{M}$ at 24 hours after plating. Multiple wounding resulted in an increase to 20 (1.4) $\mu \mathrm{M}$ nitrite after 24 hours. Incubating cells with $4 \mathrm{mM} \mathrm{ARG} \mathrm{more}$ than doubled NO production to 47 (3.7) $\mu \mathrm{M}$ nitrite $(\mathrm{p} \leqslant 0.05 v$ control media containing $0.4 \mathrm{mM}$ ARG) but BSC had no stimulatory effect on nitrite level $(24(1.2) \mu \mathrm{M})(\mathrm{n}=4)$. ARG (fig 3A) and Deta-NONOate (at 5-10 $\mu \mathrm{M}$ ) increased nitrite
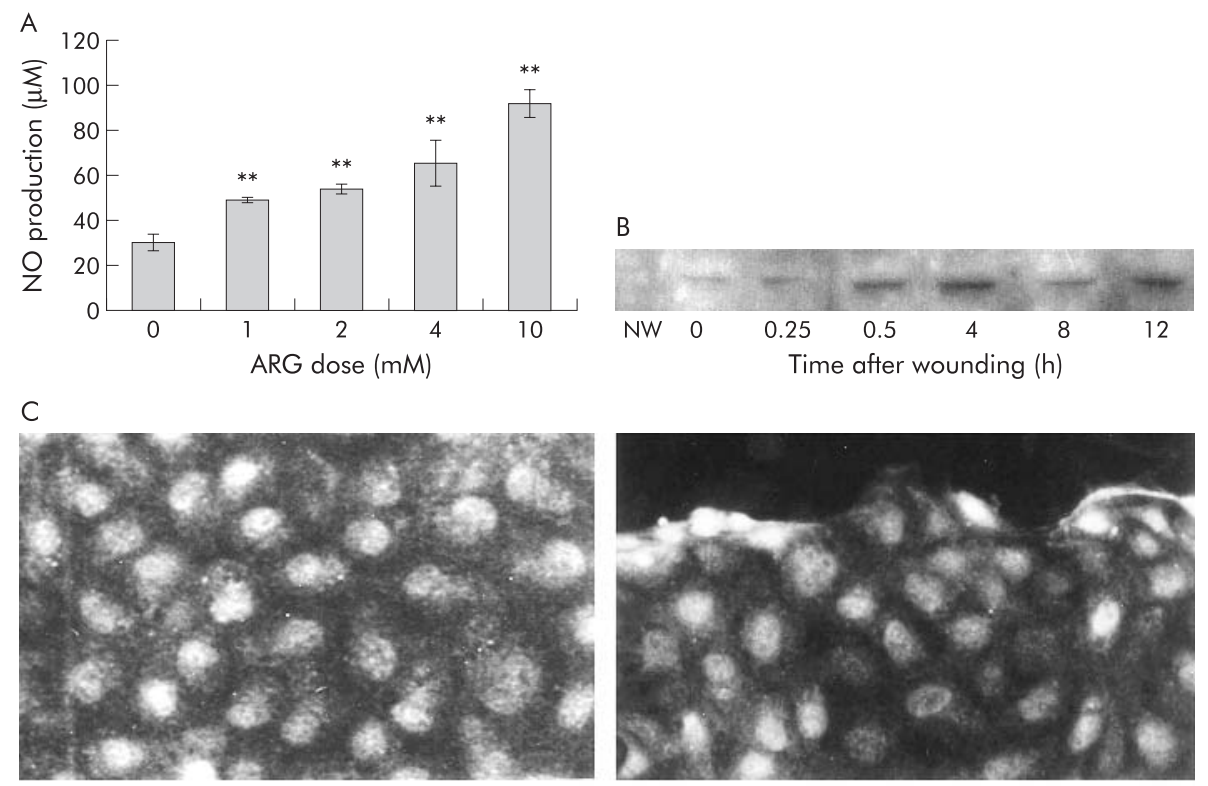

Not wounded

Control (0 hours)
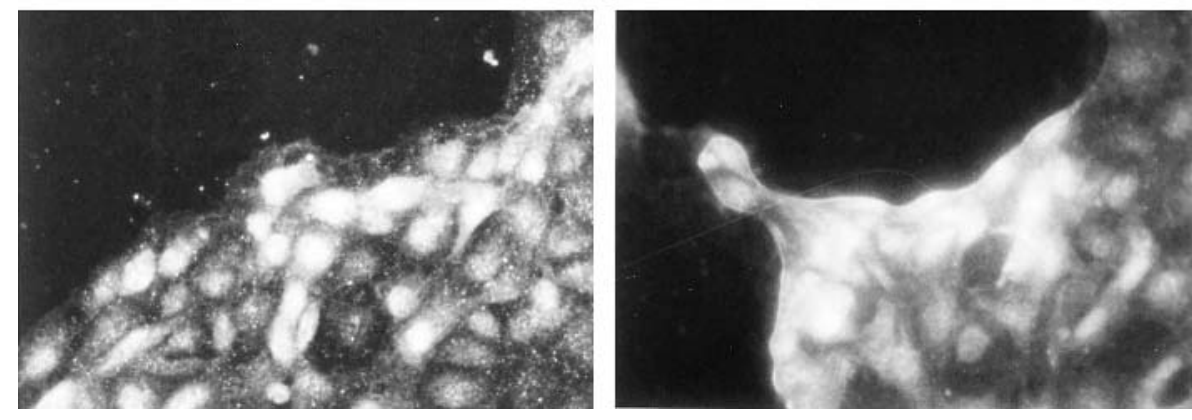

Wounded (1 hour)

Wounded (4 hours)

Figure 3 (A) L-Arginine (ARG) dose dependently increased nitrite (NO) levels in media at 24 hours. Values are means (SEM), $n=4 .{ }^{* *} p \leqslant 0.01$ compared with control wounded cells. (B) Cell wounding enhanced the level of inducible nitric oxide synthase (iNOS). Cdx 2 transformed IEC-6 cells were wounded multiple times with a plastic pipette tip and washed. At specified time intervals, cells were harvested and $100 \mu \mathrm{g}$ protein were electrophoresed and blotted with polyclonal anti-NOS II antibody. Densitometric analysis revealed maximal activation of iNOS by four hours. Results in relative densitometric values were: non-wounded (NW) $1 x$; wounded 0 min $1.7 x$; wounded 30 minutes $4.7 x$; wounded four hours $5 x$; and wounded 24 hours $3.3 \times$. (C) Cell wounding enhanced cytoplasmic expression of iNOS at the leading edge. Immunocytochemical staining of Cdx-2 transformed IEC-6 cells was preformed on unwounded and wounded cells. Weak cytoplasmic fluorescence in unwounded cells was transformed to bright cytoplasmic fluorescence which was most evident in cells at the leading edge. Cells were stained and fixed at time points after wounding, as indicated. 

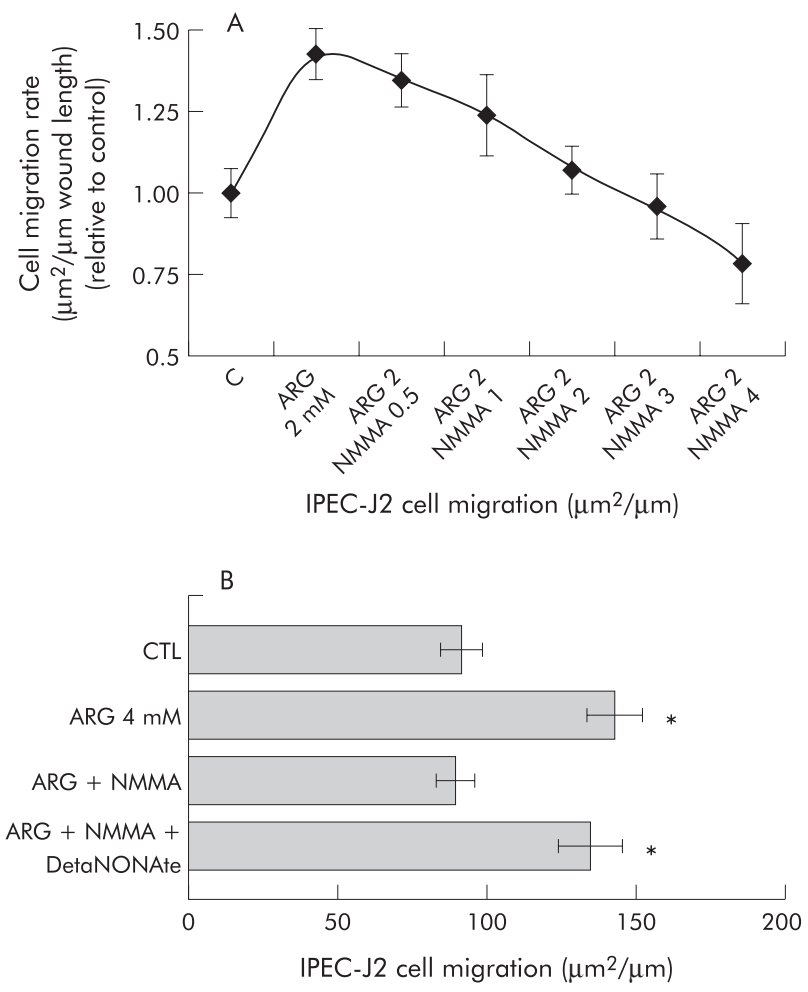

Figure 4 Effect of a nitric oxide synthase inhibitor on intestinal cell migration. $L-N^{G}$-monomethyl arginine (NMMA) was used to inhibit nitric oxide synthases while 3,3-bis(aminoethyl)-1-hydroxy-2-oxo-1-triazene (Deta-NONOate) (an NO donor) reversed the inhibition by NMMA. (A) IPEC-J2 cells were serum starved for 24 hours and then changed to Dulbecco's modified Eagle's medium with different doses of NMMA one hour before adding $2 \mathrm{mM}$ L-arginine (ARG). Subsequently, they were injured by razor wounding. Affer 24 hours, cells were fixed and migration was measured by computer assisted morphometry. "ARG 2" indicates $2 \mathrm{mM}$ ARG; the number after NMMA indicates concentration of NMMA (mM). Values are means (SEM) of three experiments. $p \leqslant 0.05$ above migration in control cells (C). (B) Inhibition of ARG stimulated migration by NMMA $(4 \mathrm{mM})$ was "rescued" by simultaneous addition of Deta-NONOate $(10 \mu \mathrm{M})$. Cells were treated one hour before and after wounding with NMMA $(4 \mathrm{mM})$, ARG $(4 \mathrm{mM})$, or ARG+NMMA plus Deta-NONOate $(10 \mu M)(n=4)$. * $p \leqslant 0.05$ compared with control cells (CTL).

levels dose dependently. (Measurement of nitrite levels with Deta-NONOate might not be accurate because the acidic conditions of the Griess reaction induce NO release from NO donors.)

Tissue injury is known to produce an increase in the level of iNOS. To determine if cell injury induced expression of iNOS, cells were multiply wounded and harvested at different times after injury (fig 3B). The results indicated that iNOS was expressed 1.8-fold at the time of wounding, 2.3-fold at 30 minutes after wounding, with a peak of 2.8 -fold at four hours, and reduced activation thereafter (fig 3B). Immunofluorescence detection of iNOS in IPEC-J2 cells (fig 3C) revealed a low baseline in unwounded resting monolayers and in freshly wounded cells. A dramatic increase in iNOS was seen in cells at the wound edge at 1-4 hours after wounding.

$\mathrm{NMMA}^{20}$ is an ARG analogue that competitively inhibits NOS. ${ }^{13}$ We studied the effect of increasing concentrations of NMMA on 2 mM ARG stimulated cell migration (fig 4A). NMMA reduced ARG stimulated IPEC-J2 cell migration in a dose dependent manner, with complete inhibition at $2 \mathrm{mM}$ NMMA. Individually given to IPEC-J2 cells in standard media, NMMA did not inhibit the basal rate of migration (data not shown, $\mathrm{n}=4$ ). NMMA completely blocked NO synthesis from ARG in IPEC-J2 cells. NMMA fully inhibited ARG stimulated nitrite production at 24 hours (wounded control cells $=10.4 \mu \mathrm{M}$ nitrite; wounded \pm ARG $(4 \mathrm{mM})=$ $25.7 \mu \mathrm{M}$ nitrite; wounded $\pm \mathrm{ARG} \pm \mathrm{NMMA}(4 \mathrm{mM})=8.2 \mu \mathrm{M}$ nitrite; wounded \pm NMMA $=4.6 \mu \mathrm{M}$ nitrite).

Similar to NMMA, the specific inhibitor of iNOS, L-N6 ( l-iminoethyl)lysine (L-Nil), inhibited ARG stimulated migration at $5 \mu \mathrm{M}$ (data not shown). These findings indicate that NO production is essential for ARG stimulated migration. To further support this relationship, we demonstrated that the NO donor Deta-NONOate individually stimulated IPEC-J2 cell migration by 1.5-fold (data not shown). NMMA inhibition of ARG stimulated migration could be "rescued" by administration of the NO donor Deta-NONOate $(50 \mu \mathrm{M}$; fig 4B). NMMA did not significantly affect BSC stimulated cell migration $(\mathrm{n}=3$, data not shown).

Additive effects of ARG+BSC on enterocyte migration $\mathrm{BSC}$ at $5 \mathrm{mg} / \mathrm{ml}$ stimulated cell migration 1.5 fold $(\mathrm{p} \leqslant 0.05)$, an effect comparable with that of $4 \mathrm{mM}$ ARG. We could not achieve saturation because of limiting solubility $(5 \mathrm{mg} / \mathrm{ml})$ although stimulation with $5 \mathrm{mg} / \mathrm{ml}$ was not significantly greater than that with $0.1 \mathrm{mg} / \mathrm{ml}$. Figure 5 shows a photomicrograph of migrating cells treated with ARG $(4 \mathrm{mM}), \mathrm{BSC}(0.1 \mathrm{mg} / \mathrm{ml})$, or combinations of these treatments. ARG plus BSC ("A+B") increased IPEC-J2 cell migration significantly more effectively than ARG or BSC alone. In three experiments of 3-4 observations each, the adjusted mean response of control cells was 60 (5) $\mu \mathrm{m}^{2} / \mu \mathrm{m}$; of ARG treated cells 88 (7) $\mu \mathrm{m}^{2} / \mu \mathrm{m}$; of BSC treated cells 107 (6) $\mu \mathrm{m}^{2} / \mu \mathrm{m}$; and of ARG+BSC treated cells 128 (6) $\mu \mathrm{m}^{2} / \mu \mathrm{m}$ wound $(p \leqslant 0.001$ for ARG+BSC compared with either ARG or BSC).

\section{ARG stimulated enterocyte migration is blocked by ODC inhibition}

ARG is a precursor of ornithine via the action of arginase(s). ${ }^{26} 27$ Ornithine derived polyamines (putrescine (PUT), spermidine, and spermine) are essential for intestinal cell migration. ${ }^{28-30}$ We postulated that inhibition of ODC, the rate controlling enzyme in polyamine biosynthesis, would abolish stimulation of migration by ARG. The ODC inhibitor DFMO was used at $5 \mathrm{mM}$, a concentration that was previously shown to maximally inhibit ODC in the IPEC-J2 cell line. ${ }^{16}$ DFMO by itself did not inhibit basal levels of migration (113 (6) $\mu \mathrm{m} / \mathrm{mm} v 106$ (6) $\mu \mathrm{m} / \mathrm{mm}$ in control cells). Failure of DFMO to fully block migration is consistent with the observation that after four days of DFMO, cellular spermine levels remained $50 \%$ of normal. ${ }^{19}$ Figure 6 A shows that ARG stimulated migration was blocked by DFMO, and that PUT rescued this DFMO effect.

High pressure liquid chromatography was used to determine if ARG treatment for 24 hours enhanced IPEC-J2 cell polyamine levels. Figure 6B shows that addition of ARG did not enhance polyamine levels. Serum induces ODC in intestinal cells. ${ }^{16}$ BSC $100 \mathrm{mg} / 100 \mathrm{ml}$ produced threefold increases in the levels of PUT, spermidine, and spermine $(p \leqslant 0.05)$. These levels were higher compared with those of freshly isolated piglet enterocytes ${ }^{21}$ but were very similar to those previously reported for cultured $\mathrm{Cdx} 2$ transformed IEC-6 cells. ${ }^{19}$

In our additional studies, high dose PUT $(0.1 \mathrm{mM})$ alone did not significantly stimulate IPEC-J2 cell migration (data not shown, $n=3$ ). These results suggest that despite a constitutive role of polyamines, the efficacy of ARG cannot be attributed to enhanced polyamine synthesis. 

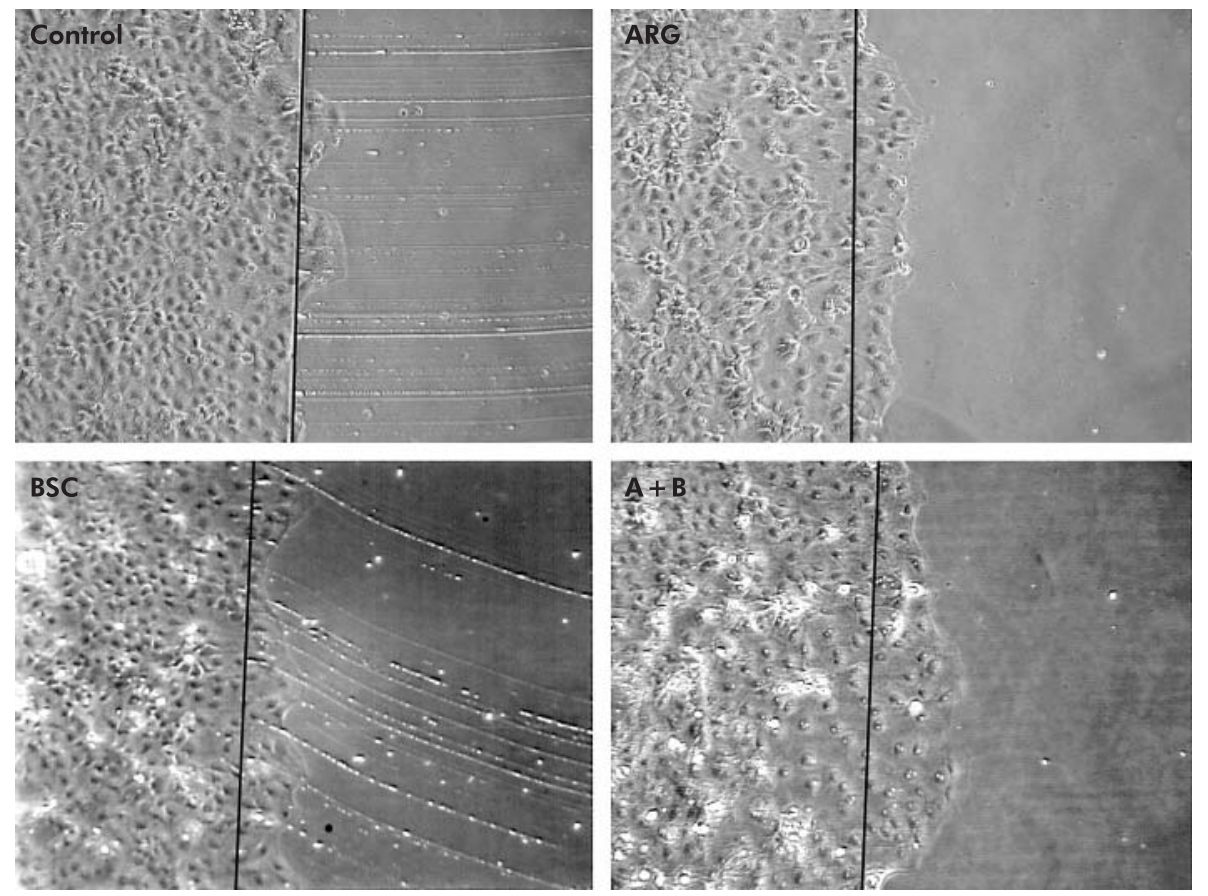

Figure 5 Additive stimulation of IPEC-J2 cell migration by L-arginine (ARG) and bovine serum concentrate (BSC). Twenty four hour serum starved cells were changed to Dulbecco's modified Eagle's medium without additives (control) or with one of the following: $4 \mathrm{mM}$ ARG (" $A^{\prime \prime}$ ); $0.1 \mathrm{mg} / \mathrm{ml} B S C$ alone $\left({ }^{\prime \prime} \mathrm{B}^{\prime \prime}\right)$; or ARG+BSC $\left(" \mathrm{~A}+\mathrm{B}^{\prime \prime}\right)$, added to cells one hour prior to wounding. After 24 hours, cells were fixed in $2 \%$ formaldehyde/phosphate buffered saline, and migration area was measured as described above. The photomicrograph represents one of six experiments in which ARG and BSC were compared with ARG+BSC. The razor scratch line is enhanced with a black line.

\section{Requirement for FAK in ARG stimulated enterocyte migration: transfection studies}

To determine if FAK phosphorylation is required for intestinal cell migration and the response to ARG, Cdx-2 transformed IEC-6 cells were transfected with a dominant negative construct of FAK mediated by adenoviral gene transfer. ${ }^{24}$ Adenovirus promoter linked to luciferase was used as a control for cells with intact FAK activity. Preliminary studies showed that control cell infection for 12 hours led to a steady rise in luciferase expression $(n=3)$. Therefore, transfections were performed for 12 hours. FAK-CD transfection reduced basal cellular migration by 33\% compared with control virus and also fully inhibited the cell migration response to ARG and BSC. In contrast, control transfection with adeno-luciferase had no inhibitory effect on the ARG response, with cells migrating at $>2 \times$ the control rate after treatment with either ARG or BSC $(p \leqslant 0.05)$ (fig 7$)$.

\section{DISCUSSION}

\section{Nitric oxide in cell migration}

One of the most important metabolites of arginine is NO which plays an important role in regulating intestinal barrier function. ${ }^{13}$ In newborn pigs, pretreatment with intravenous ARG greatly attenuated necrotising enterocolitis (NEC) produced by intraluminal acidified casein $^{31}$ and improved intestinal recovery after ischaemic damage in rats by an NOS dependent mechanism. ${ }^{90}$ Our finding that NO stimulates post-injury intestinal epithelial cell migration is consistent with several studies in other cell types. ARG, NO donors, and NO second messengers enhanced endothelial cell migration. ${ }^{11}{ }^{32} \mathrm{NO}$ was reported to inhibit cell adhesion to matrix (and activation of FAK) in renal mesangial cells, vascular smooth muscle cells, and endothelial cells. ${ }^{33-35}$ In normal renal epithelial monolayers, after wounding there is a biphasic release of NO during cell migration with peaks at
1-2 minutes and again after 2-3 hours. This NO release is accompanied by iNOS expression at the wound edge. ${ }^{11}{ }^{32} \mathrm{It}$ has been suggested that increased NO facilitates detachment and scalar movement, as opposed to vectorial movement. ${ }^{32}$

Arginine stimulated cell migration was dose dependent, with a maximal effect at $4 \mathrm{mM}$. Required doses were therefore $>40$-fold higher than serum levels in preterm infants $(94(10) \mu \mathrm{M})^{36}$ and in porcine milk $(65(5) \mu \mathrm{M}) .^{37}$ However, ARG concentrations in the intestine secondary to postprandial luminal proteolysis can be much higher-in the range $1-2 \mathrm{mM}^{2137}$-and thus our findings are physiologically relevant. We recently showed that ARG stimulates restitution of injured intestinal epithelial sheets. Gookin et al showed that the iNOS specific inhibitor L-Nil is effective in blocking ARG plus serum stimulated migration in the injured piglet ileum. ${ }^{38}$ At supraphysiological levels $(>20 \mathrm{mM})$, ARG efficacy was abolished. Although not explored, this inhibition could be secondary to inhibitory effects of high dose NO.

\section{FAK as a signalling molecule in intestinal cell migration}

Previous studies demonstrated a central role for FAK in cell migration in mesenchymal cells, such as human umbilical vein endothelial cells. Tyrosine phosphorylation of FAK correlated well with FAK activation and motility while a tyrosine kinase inhibitor blocked migration and FAK activation. ${ }^{33}$ Overexpression of FAK increased cell migration. ${ }^{39}$ In research focusing on intestinal cells, Caco-2 cell adhesion to laminin or type I collagen was shown to require tyrosine phosphorylation. ${ }^{25}$ Inhibition of FAK tyrosine phosphorylation (by transfection with FAK related non-kinase) blocked adhesion, extracellular related kinase activation, ${ }^{25}$ and cell migration. ${ }^{40}$

Our studies support a primary role for FAK in ARG stimulated small intestinal cell migration. ARG increased 

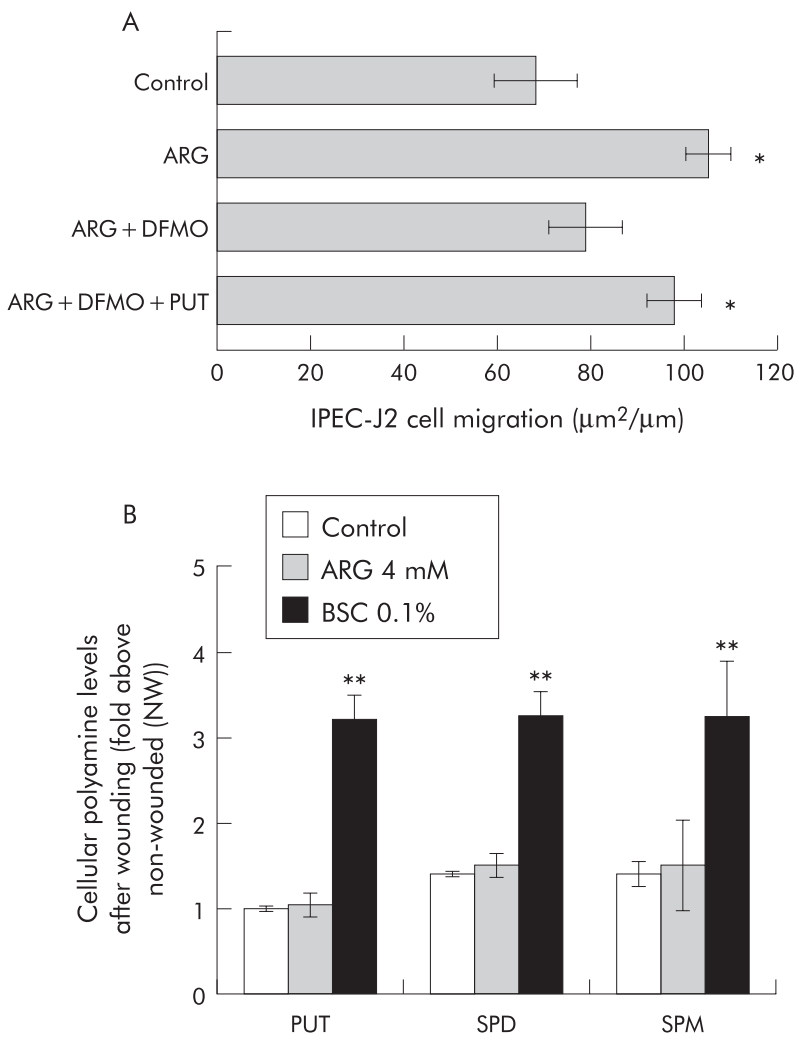

NW PUT $0.13(0.04) \mathrm{nmol} / \mathrm{mg}$ protein NW SPD $2.6(0.9) \mathrm{nmol} / \mathrm{mg}$ protein NW SPM $4.5(0.9) \mathrm{nmol} / \mathrm{mg}$ protein

Figure 6 Relationship between polyamine synthesis and cell migration in response to L-arginine (ARG). The inhibitor difluoromethyl-ornithine (DFMO $1 \mathrm{mM}$ ) was added 24 hours before the treatment of ARG $(4 \mathrm{mM})$. (A) ARG $(4 \mathrm{mM})$ stimulated migration was blocked by DFMO $(1 \mathrm{mM})$, and was "rescued" by putrescine (PUT $100 \mu \mathrm{M}) ; \mathrm{n}=4$, ${ }^{*} \mathrm{p} \leqslant 0.05$. (B) Effects of ARG (4 mM) on IPEC-J2 cellular polyamine levels. Bovine serum concentrate (BSC) $(100 \mathrm{mg} / 100 \mathrm{ml})$, which induced ornithine decarboxylase, is used as a positive control. Intracellular polyamine concentration was determined 24 hours after wounding, as described in the methods section. BSC significantly increased PUT, spermidine (SPD), and spermine (SPM) levels. Cellular polyamine levels are shown at the bottom for non-wounded (NW) cells. Bars refer to levels compared with non-wounded cells. Values are means (SEM), $n=3$. ${ }^{* *} p \leqslant 0.01$ compared with control wounded cells.

FAK tyrosine phosphorylation at early time points, with a dose dependent response in the same range that stimulates migration. Blocking FAK localisation and function by adenoviral infection with a dominant negative mutant blocked ARG stimulation. We suggest that FAK activation is an essential mechanism of ARG stimulated cell migration. Although cells can migrate in the absence of functional FAK, they do so less efficiently (fig 7), as has been demonstrated in mouse embryo fibroblasts from FAK null animals. ${ }^{41}$ Downstream targets that are effectors have been shown to bind to FAK and are activated by FAK. ${ }^{39}$ We hypothesise, as summarised in fig 8 , that FAK activation in response to ARG, $\mathrm{NO}$, or BSC enhances intestinal cell motility in a causal fashion. In this diagram, we propose that ARG not only enhances the synthesis of NO, which can stimulate FAK phosphorylation (fig 2), but may also stimulate FAK independently of NO. Consistent with this suggestion is our finding that ARG activates FAK phosphorylation at the one hour time point to a greater extent than the NO donor. Other

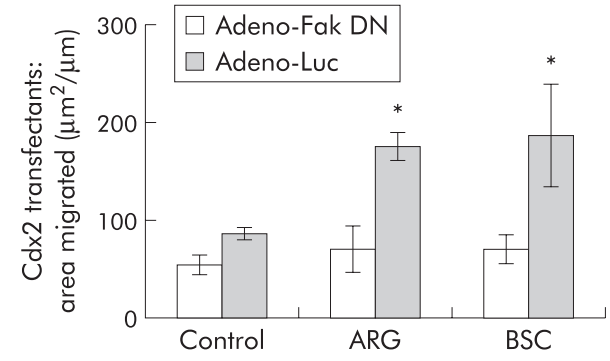

Figure 7 Cells transfected with a dominant negative version of focal adhesion kinase (FAK) do not have increased migration in response to L-arginine (ARG) or bovine serum concentrate (BSC). Cdx2 transformed IEC- 6 cells were transfected ( 12 hours) with adeno-FAK-CD (DN denotes dominant negative) or adeno-luciferase (Adeno-Luc). Subsequently, monolayers were wounded in the presence of control media (ARG $0.4 \mathrm{mM})$, media+ARG $(4 \mathrm{mM})$, or media+BSC $(0.1 \mathrm{mg} / \mathrm{ml})$. Surface area covered by migrating cells was measured 12 hours later. ${ }^{*} \mathrm{p} \leqslant 0.05$ compared with control wounded (adeno-luciferase transfected) cells.

investigators have also shown that the NO donor sodium nitroprusside mimics the effects of ARG on human umbilical vein endothelial cell migration and FAK phosphorylation, albeit with a different time course. ${ }^{42}$ Finally, NO can directly stimulate cell migration and FAK phosphorylation (fig 8).

\section{Requirement for polyamines in intestinal cell migration}

Polyamines (PUT, spermidine, and spermine) are central to the restitution process in intestinal tissues. ${ }^{28-30}$ Their synthesis from precursors such as ARG is required for migration, and inhibition of migration by the ODC inhibitor DFMO can be "rescued" by the exogenous polyamine PUT (fig 6A), via its conversion to spermine. ${ }^{43}$ Of interest, FAK signalling, including phosphorylation of paxillin, has been found to be dependent on polyamines. ${ }^{43}$ Polyamines are constitutively required for the stimulatory effect of ARG. However, polyamines can stimulate cell matrix adhesion, as proposed in fig 8. Santos et al showed that polyamine deficiency inhibited cell attachment to plastic, laminin, fibronectin, collagen IV, and Matrigel by different extents. Polyamines were essential for normal expression of the integrin subunit $\alpha 2$ but not for expression of the $\alpha$ l subunit. Thus polyamines participate in cell attachment and expression of the integrin $\alpha 2 \beta 1$, a putative receptor for collagen and laminin. ${ }^{44}$

We have shown in this study that increasing ARG levels above the basal medium concentration of $0.4 \mathrm{mM}$ did not

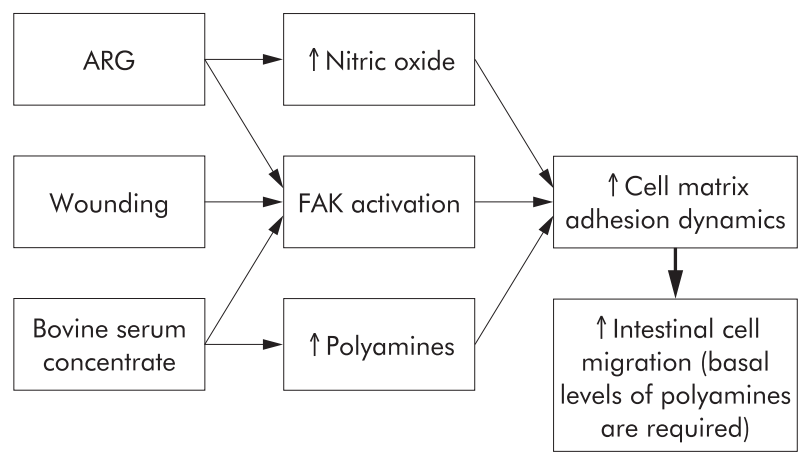

Figure 8 Schematic showing proposed mechanisms of L-arginine (ARG), nitric oxide, and bovine serum concentrate (BSC) additivity in intestinal cell migration. Focal adhesion kinase (FAK) is seen as an integrative point of convergence leading to increased cell matrix adhesion dynamics. Polyamines are required for this process but only BSC results in increased polyamine synthesis. 
increase polyamine synthesis, consistent with studies in cultured smooth muscle cells and endothelial cells. ${ }^{45-47}$ These findings may indicate that arginase rather than arginine levels limits the production of polyamines in cultured intestinal cells, as recently reported for cultured endothelial cells. $^{48}$

\section{Clinical implications of ARG in paediatric intestinal disease}

ARG metabolism is of major importance to neonatal nutrition. ${ }^{12}{ }^{49}$ ARG serum levels dwindle below normal levels in preterm infants that later develop NEC, and these levels are in the range of $0.04-0.06 \mathrm{mM}$, well below postprandial luminal levels (see above) and below the maximal levels to stimulate intestinal cell migration shown in these studies. ${ }^{36} 50$ A recent prospective controlled trial of ARG versus nonessential amino acid therapy for preterm infants showed that ARG supplementation significantly reduced the incidence of NEC. ${ }^{51}$ Our investigations have identified the cellular mechanism of a restitution enhancing effect of ARG. Our studies show that the magnitude of ARG stimulated cell migration equals that of growth factors and prostaglandins. Further defining the role of ARG in restitution may provide a rationale for administering exogenous free ARG and BSC (or components of BSC) in treatment solutions for patients with intestinal injury.

\section{ACKNOWLEDGMENTS}

Grant support was from NIH DK57774-01 to JMR, USDA 2000-02092 to RAA, USDA 2003-03243 to GYW, NIH HL03299 to LHR, NIH DK34987 Center Grant, and NIH grant CA65910 to WCG. The authors thank Dr Om Prakash and the Ochsner Medical Editing office for reviewing and editing this manuscript.

\section{Authors' affiliations}

J M Rhoads, Q Fu, Department of Pediatrics, and Center in Gastrointestinal Biology and Disease, University of North Carolina, Chapel Hill, North Carolina, USA, and Department of Pediatrics, Ochsner Clinic Foundation, New Orleans, Louisiana, USA

W Chen, Department of Pediatrics, and Center in Gastrointestinal Biology and Disease, University of North Carolina, Chapel Hill, North Carolina, USA

J Gookin, A T Blikslager, R A Argenzio, Center in Gastrointestinal Biology and Disease, University of North Carolina, Chapel Hill, North Carolina, USA, and Departments of Anatomy, Physiological Sciences, and Radiology and Clinical Sciences, North Carolina State University College of Veterinary Medicine, Raleigh, North Carolina, USA

G Y Wu, Faculty of Nutrition, Texas A\&M University, College Station, Texas, USA

R A Rippe, Department of Medicine, and Center in Gastrointestinal Biology and Disease, University of North Carolina, Chapel Hill, North Carolina, USA

W G Cance, Department of Surgery, University of Florida, Gainesville, Florida, USA

E M Weaver, LG Laboratories, Ames, lowa, USA

L H Romer, Departments of Anesthesiology, Cell Biology, and Pediatrics, Johns Hopkins University, Baltimore, Maryland, USA

\section{REFERENCES}

1 Wilson AJ, Gibson PR. Epithelial migration in the colon: filling in the gaps. Clin Sci 1997;93:97-108.

2 Sieg DJ, Hauck CR, llic D, et al. FAK integrates growth-factor and integrin signals to promote cell migration. Nature Cell Biol 2000;2:249-56.

3 Romer LH, McLean N, Turner CE, et al. Tyrosine kinase activity, cytoskeletal organization, and motility in human vascular endothelial cells. Mol Biol Cell 1994;5:349-61.

4 Schwartz MA, Schaller MD, Ginsberg MH. Integrins: emerging paradigms of signal transduction. Annu Rev Cell Dev Biol 1995;11:549-99.

5 Burridge K, Chrzanowska-Wodnicka M. Focal adhesions, contractility, and signaling. Annul Rev Cell Dev Biol 1996;12:463-518.

6 Turner CE. Paxillin and focal adhesion signalling. Nature Cell Biol 2000;2:E231-6.
7 Schaller MD, Borgman CA, Cobb BS, et al. pp125FAK, a structurally unique protein tyrosine kinase associated with focal adhesions. Proc Natl Acad Sci USA 1992;89:5192-6.

8 Schaller MD, Otey CA, Hildebrand JD, et al. Focal adhesion kinase and paxillin bind to peptides mimicking beta integrin cytoplasmic domains. J Cell Biol 1995;130:1181-7

9 Raul F, Galluser M, Schleiffer R, et al. Beneficial effects of L-arginine on intestinal epithelial restitution after ischemic damage in rats. Digestion 1995;56:400-5.

10 Schleiffer R, Raul F. Prophylactic administration of L-arginine improves the intestinal barrier function after mesenteric ischaemia. Gut 1996;39:194-8.

11 Noiri E, Hu Y, Bahou WF, et al. Permissive role of nitric oxide in endothelininduced migration of endothelial cells. J Biol Chem 1997;272:1747-52.

12 Wu G, Meininger CJ, Knabe DA, et al. Arginine nutrition in development, health and disease. Curr Opin Clin Nutr Metabol Care 2000;3:59-66.

13 Alican I, Kubes P. A critical role for nitric oxide in intestinal barrier function and dysfunction. Am J Physiol 1996;270:G225-37.

14 McCormack SA, Viar MJ, Johnson LR. Migration of IEC-6 cells: a model for mucosal healing. Am J Physiol 1992;263:G426-35.

15 Hunt E, Fu Q, Armstrong MU, et al. Oral bovine serum concentrate improves cryptosporidial enteritis in calves. Pediatr Res 2002;51:370-6.

16 Kandil HM, Argenzio RA, Chen W, et al. L-glutamine and L-asparagine stimulate ODC activity and proliferation in a porcine jejunal enterocyte line. Am J Physiol 1995;269:G591-9.

17 Berschneider HM, Powell DW. Fibroblasts modulate intestinal secretory responses to inflammatory mediators. J Clin Invest 1992;89:484-9.

18 Silberg DG, Swain GP, Suh ER, et al. Cdx1 and cdx2 expression during intestinal development. Gastroenterology 2000;119:961-71.

19 Rao JN, Li J, Li L, et al. Differentiated intestinal epithelial cells exhibit increased migration through polyamines and myosin II. Am J Physiol 1999:277:G1149-58

20 Edwards RM, Stack EJ, Trizna W. Interaction of L-arginine analogues with L-arginine uptake in rat renal brush border membrane vesicles. J Pharmacol Exp Ther 1998;285:1019-22.

21 Wu G, Flynn NE, Knabe DA. Enhanced intestinal synthesis of polyamines from proline in cortisol-treated piglets. Am J Physiol Endocrinol Metab 2000;279:E395-402

22 Wu G, Pond WG, Flynn SP, et al. Maternal dietary protein deficiency decreases nitric oxide synthase and ornithine decarboxylase activities in placenta and endometrium of pigs during early gestation. J Nutr 1998; 128:2395-402.

23 Gilmore AP, Romer LH. Inhibition of focal adhesion kinases (FAK) signaling in focal adhesions decreases cell motility and proliferation. Molec Biol Cell 1996;7:1209-24.

24 Xu LH, Yang X, Craven RJ, et al. The $\mathrm{COOH}$-terminal domain of the focal adhesion kinase induces loss of adhesion and cell death in human tumor cells. Cell Growth Differ 1998;9:999-1005.

25 Sanders MA, Basson MD. Collagen IV-dependent ERK activation in human Caco-2 intestinal epithelial cells requires focal adhesion kinase. J Biol Chem 2000;275:38040-7.

26 Wu G, Borbolla AG, Knabe DA. The uptake of glutamine and release of arginine, citrulline and proline by the small intestine of developing pigs. J Nutr 1994; 124:2437-44.

27 Wu G, Knabe DA, Flynn NE, et al. Arginine degradation in developing porcine enterocytes. Am J Physio 1996;271:G913-19.

28 McCormack SA, Wang J-Y, Johnson LR. Polyamine deficiency causes reorganization of F-actin and tropomyosin in IEC-6 cells. Am J Physiol 1994:267:C715-22

29 McCormack SA, Wang J-Y, Viar MJ, et al. Polyamines influence transglutaminase activity and cell migration in two cell lines. Am J Physiol 1994;267:C706-14

30 Wang J-Y, Viar MJ, Li J, et al. Polyamines are necessary for the normal expression of the transforming growth factor-beta gene during cell migration. Am J Physiol 1997;272:G713-20.

31 Dilorenzo M, Bass J, Krantis A. Use of L-arginine in the treatment of experimental necrotizing enterocolitis. J Pediatr Surg 1995;30:235-40.

32 Noiri E, Peresleni T, Srivastava N, et al. Nitric oxide is necessary for a switch from stationary to locomoting phenotype in epithelial cells. Am J Physiol 1996;270:C794-802

33 Fang S, Sharma RV, Bhalla RC. Endothelial nitric oxide synthase gene transfer inhibits platelet-derived growth factor-BB stimulated focal adhesion kinase and paxillin phosphorylation in vascular smooth muscle cells. Biochem Biophys Res Commun 1997;236:706-11

34 Kaur K, Yao J, Pan X, et al. NO decreases phosphorylation of focal adhesion proteins via reduction of $\mathrm{Ca}$ in rat aortic smooth muscle cells. Am J Physiol 1998:274:H1613-19.

35 Yao J, Schoecklmann HO, Prols F, et al. Exogenous nitric oxide inhibits mesangial cell adhesion to extracellular matrix components. Kidney Int 1998;53:598-608.

36 Becker RM, Wu G, Galanko JA, et al. Reduced serum amino acid concentrations in infants with necrotizing enterocolitis. J Pediatr 2000;137:785-93

37 Wu G, Knabe DA. Free and protein-bound amino acids in sow's colostrum and milk. J Nutr 1994;124:415-24.

38 Gookin JL, Rhoads JM, Argenzio RA. Inducible nitric oxide synthase mediates early epithelial repair of porcine ileum. Am J Physiol Gastrointest Liver Physiol 2002;283:G157-68.

39 Cary LA, Chang JF, Guan JL. Stimulation of cell migration by overexpression of focal adhesion kinase and its association with Src and Fyn. J Cell Sci 1996; 109: 1787-94. 
40 Yu CF Sanders MA, Basson MD Human caco- 2 motility redistributes FAK and paxillin and activates p38 MAPK in a matrix-dependent manner. Am J Physiol Gastrointest Liver Physiol 2000;278:G952-66.

41 Ilic D, Furuta Y, Kanazawa S, et al. Reduced cell motility and enhanced focal adhesion contact formation in cells from FAK-deficient mice. Nature 1995;377:539-44.

42 Goligorsky MS, Abedi H, Noiri E, et al. Nitric oxide modulation of focal adhesions in endothelial cells. Am J Physiol 1999;276:C1271-81.

43 Yuan Q, Viar MJ, Ray RM, et al. Putrescine does not support the migration and growth of IEC-6 cells. Am J Physiol Gastrointest Liver Physiol 2000;278:G49-56.

44 Santos MF, Viar MJ, McCormack SA, et al. Polyamines are important for attachment of IEC-6 cells to extracellular matrix. Am J Physiol 1997:273(1Pt 1):G175-83.

45 Wei LH, Wu G, Morris SM jr, et al. Elevated arginase I expression in rat aortic smooth muscle cells increases cell proliferation. Proc Natl Acad Sci USA $2001 ; 98: 9260-4$.
46 Crouch CF, Woode GN. Serial studies of virus multiplication and intestinal damage in gnotobiotic piglets infected with rotavirus. J Med Microbiol 1978; 11:325-34

47 Li H, Meininger CJ, Hawker JR jr, et al. Regulatory role of arginase I and II in nitric oxide, polyamine, and proline syntheses in endothelial cells. Am J Physio Endocrinol Metab 2001;280:E75-82.

48 Li H, Meininger CJ, Kelly KA, et al. Activities of arginase I and II are limiting for endothelial cell proliferation. Am J Physiol Regul Integr Comp Physiol 2002;282:R64-9

49 Wu G, Morris SM ir. Arginine metabolism: nitric oxide and beyond. Biochem J 1998;336:1-17.

50 Zamora SA, Amin HJ, McMillan DD, et al. Plasma L-arginine concentrations in premature infants with necrotizing enterocolitis. J Pediatr 1997;131:226-32

51 Amin HJ, Zamora SA, McMillan DD, et al. Arginine supplementation prevents necrotizing enterocolitis in the premature infant. J Pediatr 2002; 140:425-31. 